\title{
Polio phases in Pakistan a decade's journey at one glance: A succinct report
}

\author{
Rizwana Akhter Memon ${ }^{1 *}$, Farah Naz Memon ${ }^{2}$, Rana Saba Sultan ${ }^{1}$ and \\ Hafeez Ahmed Memon ${ }^{3}$ \\ 1. Department of Sociology.University Road, Karachi, 7400, Pakistan \\ 2. Pakistan Health Research Council, Islamabad-Pakistan \\ 3. Pakistan Institute of Medical Sciences (PIMS), Islamabad-Pakistan \\ *Corresponding author's email: drmemonrizwana@gmail.com \\ Citation \\ Rizwana Akhter Memon, Farah Naz Memon, Rana Saba Sultan and Hafeez Ahmed Memon. Polio phases in \\ Pakistan a decade's journey at one glance: A succinct report. Pure and Applied Biology. Vol. 8, Issue 2, pp1801- \\ 1808. http://dx.doi.org/10.19045/bspab.2019.80123
}

\begin{tabular}{llll}
\hline \hline Received: 01/04/2019 & Revised: 20/06/2019 & Accepted: 24/06/2019 & Online First: 28/06/2019 \\
\hline
\end{tabular}

\section{Abstract}

Poliomyelitis (Polio) is one of the ancient diseases, based on its strong infectivity and permanent deformities/deaths among under-five age children is still considered as a major public health threat globally. On historical timeline, Polio is divided into three phases; Endemic phase, Epidemic phase, and Vaccination phase. To explore all historical phases in brief concerning the current scenario so that decade's journey can be assessed at once for future planning. Secondary data from authentic internet sources were gathered to find out key points, and a brief report is prepared. Actual origin of the disease is unknown, but its endemic phase remained in overcrowded areas where human's agglomeration was increased. Endemic phase remained scattered in different areas of the globe from antiquity era until the mid of nineteenth century when relatively fewer paralytic cases were noticed. After that, outbreaks occur on a larger scale by crossing many geographical areas. This epidemic phase remained violent until mid of the twentieth century. The third phase started with the introduction of vaccines in 1955. After advancements in vaccines and the launch of Global Polio Eradication Initiative (GPEI) in 1988, polio prevalence started reducing in richer countries followed by poorer countries around the globe. Currently, there is a $99.9 \%$ reduction in polio cases around the world; however, it remains in the endemic phase in Pakistan and Afghanistan. The situation is a continuous threat for our country as it could be converted from endemic to epidemic phase. However, Pakistan government's efforts on the application of additional strategies of Global Polio Eradication Initiative (GPEI) such as; active surveillance, real-time risk assessment, assurance of high -quality data have shown a great hope that it will be the world's fourth and final phase of "Polio Eradication Phase".

Keywords: Decades; Global Polio Eradication Initiative (GPEI); Pakistan; Phases; Polio

\section{Introduction}

Polio (also known as poliomyelitis) is a viral disease caused by a virus that belongs to Enterovirus C, family Picornaviridae. Poliovirus is a RNA (Ribonucleic Acid) virus that had been classified into three serotypes based on capsid proteins named PV1, PV2, and PV3 [1]. Poliovirus transmission is usually via the fecal-oral route. Though polio is preventable, once contracted, it can lead to mortality or major morbidity because of onset of acute-flaccid paralysis [2]. Two 
types of polio vaccines are currently effective to inhibit the onset of disease, i.e., an inactivated injectable poliovirus (IPV) and a live attenuated oral poliovirus vaccine (OPV) [3]. Poliovirus has been eliminated from all over the world except Pakistan, Nigeria, Afghanistan, Cameroon, Syria, Ethiopia, Israel, Equatorial Guinea, and Somalia [4].

In order to control the polio disease on the globe, the Global Commission for the Certification of the Eradication of Poliomyelitis (GCC) was constituted in 1995 [5]. This commission (GCC) framed the vital strategies and monitoring operations to certify polio eradicated zones. The commissions' basic principles were based on the World Health Organization (WHO) directions for the abolition of wild poliovirus (WPV), which were: (a) to expand surveillance systems (including AFP surveillance); (b) to attain and continue high routine immunization coverage and (c) to manner supplementary immunization activities (SIAs), together with national immunization days (NIDs) in all widespread zones and mopping-up immunization in high risk zones in little incidence countries [6]. Significant growth was made to achieve universal abolition. Nevertheless, some (specific) areas remain to cause distress. By the commencement of 2015, Pakistan and Afghanistan sustained to have a rotation of Wild Poliovirus (WPV) type 1 (WPV1) [7]. In 2002, WHO declared Europe as polio-free that has maintained this status until today [6]. In 2010, WPV1 imported from Pakistan caused a significant occurrence of disease in Tajikistan that was also leaked to neighboring countries [8]. In 2013-14, WPV1 was identified in sewage water in Israel [9]. In the same years, Syria, as well as Iraq, also recognized the poliovirus circulation and reported cases in their territories $[9,10]$. In 2014, WPV was mistakenly released into a river from a factory in Belgium that flows through densely populated areas of
Netherlands [11]. In the current review, we have assessed the polio history and eradication progress in Pakistan that is in line with the directions of WHO to make the area entirely free from polio.

\section{History}

Poliomyelitis, although eliminated from most of the world, remained a major public health challenge in Pakistan. Poliomyelitis, generally called Polio, is one of the ancient crippling diseases of children under five years of age, having potential to paralyze limbs, damaging brain and often the death of the affected child [12]. In the early to midtwentieth century, polio was one of the epidemic diseases fearing most of the industrial countries around the globe by paralyzing a huge number of children per year. During those days, medical practitioners and researcher struggled to find out the cause and the remedies for prevention and treatment of that fatal condition $[13,14]$. Epidemic in the United States created a challenge to fight against this disease at priority bases therefore in 1938 National Foundation for Infantile Paralysis was established by American President $\mathrm{Mr}$. Franklin D. Roosevelt to begin the research on that issue [15]. Funding was supported by American people's generosity by creating a funding campaign. Mr. John Salk was the person who found different polioviruses and him along with his team he soon became successful in discovering a vaccine which is after his name as "Salk Vaccine", after that vigilant work was done around the globe for the elimination of this fatal disease $[16,17]$.

\section{Polio epidemiology}

In the history of polio epidemiology, a considerable variation is seen in different decades, keeping in view polio history is divided into three phases; endemic phase, epidemic phase, and vaccination phase [16]. Phase One or the "Endemic Phase" started from the earliest times of human society till the end of the nineteenth century. It is 
assumed that poliovirus remained endemic for centuries because during early days there were scattered small group societies; therefore, people were hardly getting a larger number of transmissions of most of the communicable the diseases. For that reason, the diseases like polio, smallpox, measles and other respiratory tract infections remain isolated until the civilization of human societies to live in larger population areas where, hygiene, food scarcity, animals and pets close contacts attributes the spread of microorganisms [18]. Since there were no vaccines available during those days, virus transmission became rapid [19]. Hence, from endemic to "epidemic phase" was observed in the late nineteenth to the early twentieth century in some countries such as the United States, Norway, and Sweden [20].

Control on epidemic was initiated by the introduction of very effective vaccines "Vaccination Phase" by the joint action of many countries on the poliovirus and other attributable factors to break the chain of transmission of infection [18]. As a result, polio was soon eliminated from most of the world [21].

After that, rapid progress has been noticed until 2017 when the number of paralytic cases has been reduced by $99.9 \%$; however, poliovirus remained prevalent in only three countries of the world, named Nigeria, Afghanistan, and Pakistan [20].

In the developing countries, especially in tropical areas it took longer time to remain a major public health issue. To find out the status, several surveys were conducted, which proves polio prevalence in the developing countries. Findings of Lameness survey [22] conducted in 1970s revealed that 1 child in every 100 to 200 children was paralyzed in every year in those countries which were a huge burden and according to World Health Organization estimated cases of paralytic disease/year were approximately 650,000 /year [23]. On the bases of
Lameness, survey finding conducted in 1970s routine immunization was initiated under a national immunization program around the world to control the disease.

\section{Factors responsible for Polio incidence} around the globe Vs Pakistan

A study [24] reported that percent of forest cover, percent of people with contact to better sanitation services, and population thickness were observed as the topmost three imperative variables with the contribution of $43 \%, 54 \%$, and $64 \%$ respectively for the globe (Table 1). For only 29 percent of countries, percent urban population growth and per capita unvaccinated births were also recognized as noteworthy factors for incidence of polio. Climatic changes steadily had the least important factor among the predictors on the globe. The single random forests model fitted to countries altogether also exhibited comparable outcomes to those for country-specific fits. However, the percentage of alteration elucidated by the single model was only $21 \%$. Since 2015 , the occurrence of polio had been limited to Africa continent and Pakistan and Afghanistan as well [25]. In correlation of epidemiological theory [26], Noori et al. [24] detected a significant relationship between the rate of unvaccinated births and polio incidence. Thus, increased vaccination had been regarded as a tool for the reduction of polio incidences. This theory could be validated through the available data from some African countries like Mali, Burkina Faso, and Afghanistan was a threshold in unvaccinated births was recognized and being related to polio cases [27].

On the other hand, a number of factors are responsible for increasing incidence and prevalence of polio in Pakistan such as; United State and India supported war on terror, cross-border movement with neighborhood country Afghanistan, lack of funds because of investment on security issues, illiteracy of local people, lack of 
modern communication tools, lack of commutation and transportation in far-away areas, deliberately cutting this region from the other parts of modern world, selfproclaimed religious scholars, poor governmental policies which don't restrict the activities of unauthentic religious scholars, propaganda of Indian-supported media. Another most important issue is misconception regarding polio vaccines that it is causing infertility and is not halal. On the other hand, spread of rumors in the religiously conscious people and spread of opposite research related to negative health effects of polio vaccines, inactive role of media and television and insecurity of vaccinators in the field nailed negative effects on polio eradication efforts [28].

Table 1. Countries (\%) having each predictor as their top three vital factors among regions and within each region based on the random forests model [24]

\begin{tabular}{|c|c|c|c|c|c|c|c|}
\hline Variables & $\begin{array}{c}\text { All } \\
\text { Regions }\end{array}$ & African & $\begin{array}{c}\text { Eastern } \\
\text { Mediterranean }\end{array}$ & $\begin{array}{c}\text { South- } \\
\text { East Asia }\end{array}$ & $\begin{array}{l}\text { Western } \\
\text { Pacific }\end{array}$ & Americas & Europe \\
\hline $\begin{array}{c}\% \text { of people with } \\
\text { access to improved } \\
\text { sanitation facilities } 0\end{array}$ & 0.54 & 0.53 & 0.31 & 0.57 & 0.67 & 0.83 & 0.67 \\
\hline$\%$ Forest land & 0.43 & 0.53 & 0.15 & 0.14 & 0.33 & 0.83 & 0.67 \\
\hline$\%$ Arable land & 0.2 & 0.18 & 0.31 & 0.43 & 0 & 0 & 0.33 \\
\hline per capita GDP & 0.25 & 0.24 & 0.31 & 0.29 & 0.33 & 0 & 0.33 \\
\hline Population density & 0.64 & 0.71 & 0.62 & 0.43 & 0.5 & 0.67 & 0.67 \\
\hline $\begin{array}{l}\text { \% Rural population } \\
\text { growth }\end{array}$ & 0.26 & 0.26 & 0.23 & 0.57 & 0.33 & 0 & 0 \\
\hline $\begin{array}{c}\% \text { Urban population } \\
\text { growth }\end{array}$ & 0.29 & 0.21 & 0.46 & 0.14 & 0.5 & 0.33 & 0.33 \\
\hline Average temperature & 0.06 & 0.09 & 0.8 & 0 & 0 & 0 & 0 \\
\hline Total precipitation & 0.04 & 0.06 & 0.08 & 0 & 0 & 0 & 0 \\
\hline $\begin{array}{c}\text { per capita } \\
\text { unvaccinated births }\end{array}$ & 0.29 & 0.21 & 0.46 & 0.43 & 0.33 & 0.33 & 0 \\
\hline
\end{tabular}

\section{Progress of Polio eradication programme}

Before Global Polio initiative in 1988, polio paralyzed more than 1000 children each day worldwide, however, after that initiative and with the help of more than 200 countries along with 20 million volunteers, about 2.5 billion children had immunized against poliovirus. In this initiative, more than 11 billion US\$ has been utilized till recent past $[29,30]$.

In spite of passing decades in the utilization of many resources for advancements in immunization programs, the story in few countries like Pakistan is still going on from endemic to epidemic phases. According to WHO there are only two countries (Pakistan and Afghanistan) which are still showing some local context of challenges such as political conflicts, hard to reach areas and flaws in health systems deliveries [31]. In Pakistan, polio eradication summary from 1970 to 2018 has been summarized in (Figure 1) [32].

\section{Overall discussion on polio \& Pakistan}

Pakistan is one the two countries where polio is still an endemic phase and remains a major threat for the word to convert into an epidemic at any point in time keeping in view that if a single child remains infected the risk to infect other children around the world will remain constant. Government of Pakistan is struggling hard to achieve polio-free status with the support of WHO, UNICEF, and other key partners of Global Polio Eradication Initiative GPEI. With the result of that hard struggle, the incidence of polio is successfully decreasing from 20,000 
cases/year in 1990 to 12 cases in 2018 [17, 33].

Even though most of the areas of Pakistan are free of poliomyelitis, yet the challenge to eradicate it is still on the top of priorities, since there is always a risk to overlook the threat of transmission of this dangerous virus to the polio-free zones of Pakistan. On and off confirmation of cases of this crippling condition and positive results from sewage is being reported from different regions of Pakistan; keeping the alarming condition for the national as well as concerned international authorities [34]. Moreover, resistance from the people to vaccinate their children especially, against polio is remained a major obstacle due to lack of knowledge and awareness. On the other hand, lack of interest in major hospital facilities, staff absenteeism, and overburdened lady health workers created the situation worst [35]. The restraints of the polio eradication program have been summarized in (Figure 2) [36]. Till recent past, apart from the continuous support from the Global Polio Eradication Initiative (GPEI) the targeted achievements of Pakistan Polio eradication program remained unsatisfied [37]. Community behaviors, beliefs, cultural myths, political commitments, nonseriousness of the private sector, conflicts, and security of staff remained some of the reasons behind the failure of the initiative strategies in the past. As far as peoples concern regarding halal or haram vaccine it is now clearly reported by WHO Summary report by consultative Islamic scholars that oral polio vaccine is neither haram, nor causing infertility, early adulthood or any health hazard [38].

Currently great progress is noted, and according to the Pakistan Polio update sheet published in January 2019 [29] there is about 96\% reduction in polio cases since 2014. According to that update, four cases were reported out of them three cases were from Khyber Pakhtunkhwa (Bannu, Hangu, and Bajour) and one case from Punjab (Lahore). Moreover, in quick response to the highly sensitive surveillance system enable the program to detect $45 \%$ positive samples of wild poliovirus from the environment. Based on said surveillance, a detailed field investigation on gap analysis was carried out, and a fully accountable strategic plan is initiated to target around 13.32 million underfive children for vaccination.

\section{Way forward}

Currently, along with the global partners to work as a team under one umbrella, polio program is working on active surveillance, high-quality data, real-time risk assessment and many other strategies to response on routine immunization and outbreak management to systematically address the policy to reach all missed children [30]. "Vaccinating children on the move" the new initiative started in the strategy across the country will vaccinate the children at the transit points at highways, railways and bus stations will no doubt help to add a good number vaccinated children [31].

Pakistan government's continuous efforts along with support from GPEI, 260,000 frontline workers, 2,100 social mobilizers and with $95 \%$ vaccine acceptance rate; the polio program will hopefully be successful in the near future to eradicate this crippling disease from the region and enjoy polio-free status [30].

In this way, it can be only possible for the world to see the fourth and the final phase of the "Polio eradication phase". 


\section{Timeline for Polio Eradication in Pakistan}

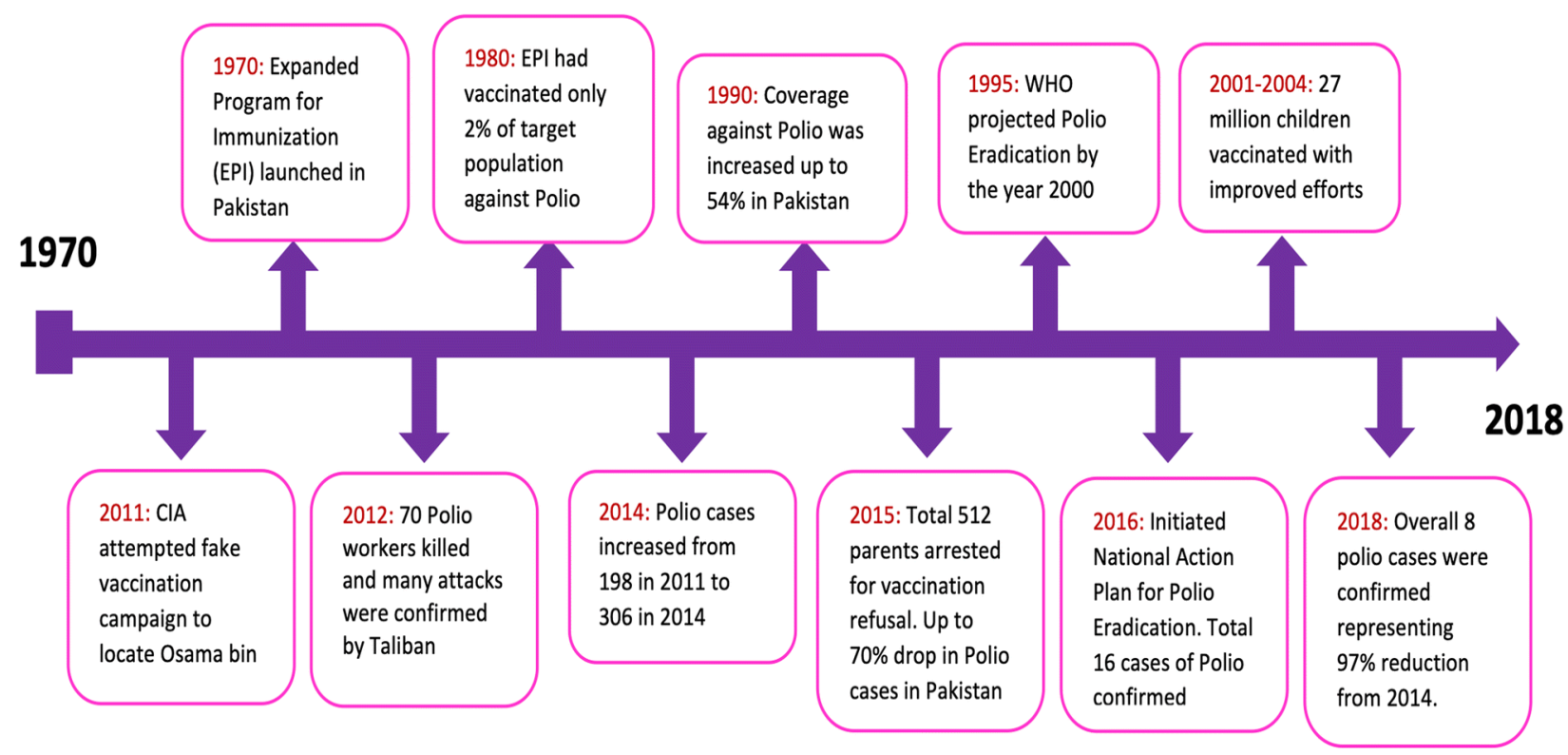

Figure 1. Timeline summary of polio eradication in Pakistan [31].

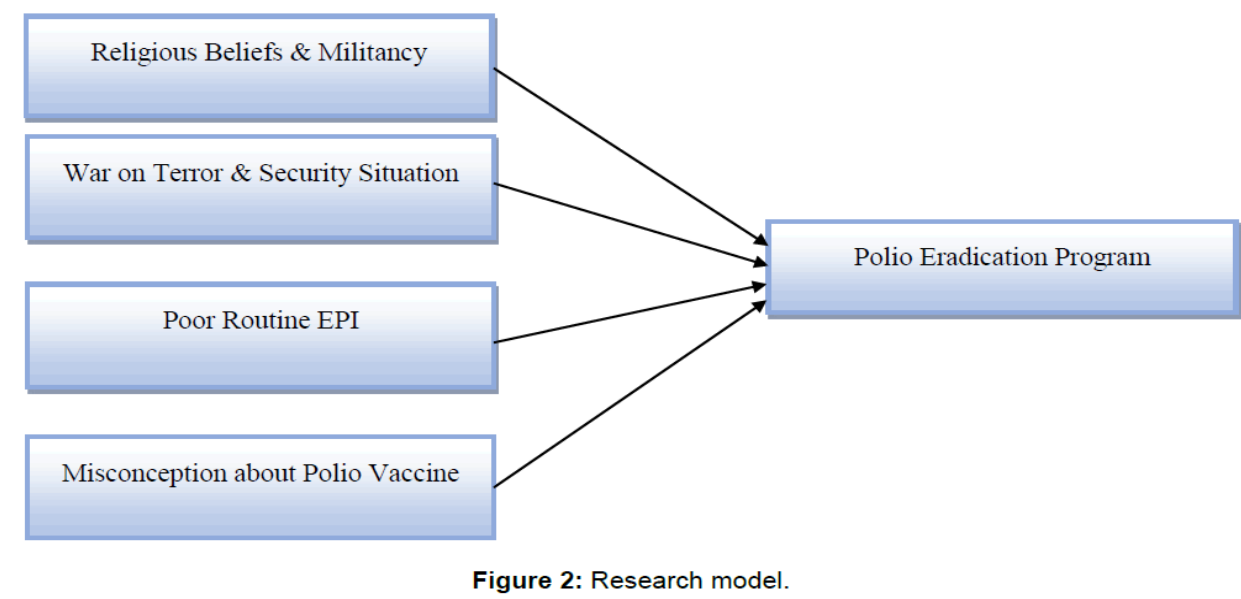

Figure 2. Research model showing constraints of the polio eradication program in Pakistan [35]. Note: EPI stands for extended program for immunization

\section{Conclusion}

In 2015, 54 cases of polio were reported all over Pakistan, followed by 20 in 2016 and 12 in 2018. This seems a tremendous achievement of government initiatives. However, again occurrence of 10 cases by 2019 indicted that Pakistan's Polio Eradication Program still required more intention and efforts, particularly in terms of strict monitoring and surveillance of high-risk areas. Additionally, the motivation of the public by religious leaders to cut the misconception of peoples and truthful dialogues with the parent groups refusing vaccination is necessary to achieve the target of polio-free Pakistan.

\section{Authors' contributions}

Conceived and designed the experiments: RA Memon \& FN Memon, Analyzed the data: RA Memon, HA Memon \& RS Sultan, Wrote the paper: RA Memon \& FN Memon. 


\section{References}

1. World Health Organization (2014) WHO statement on the meeting of the international health regulations emergency committee concerning the international spread of wild poliovirus, WHO. https://www.who.int/mediacentre/news/st atements/2014/polio-0140505/en/. Accessed 14 Jan 2019.

2. Howard RS (2005). Poliomyelitis and the post-polio syndrome. BMJ 330 .

3. US Centers for Disease Control and Prevention (2008). Manual for the surveillance of vaccine-preventable diseases. CDC. Website, https://www.cdc.gov/vaccines/pubs/survmanual/front-portion.html. Accessed 14 Jan 2019.

4. World Health Organization (2017). Statement of the 14th IHR emergency committee regarding the international spread of poliovirus. WHO Website, http:// www.who.int/mediacentre/news/statement s/2017/14th-ihr-polio/en/. Accessed 14 Jan 2019.

5. Global Polio Eradication Initiative. Polio this week. (2015). [Accessed 15 Oct 2015]. Available from: http://www. polioeradication.org/Dataandmonitoring/P oliothisweek.aspx

6. World Health Organization (WHO). (1995). Report of the 1st Meeting of the Global Commission for the Certification of the Eradication of Poliomyelitis [internet]. Geneva. [Accessed 15 Oct 2015]. Available from: http://www.polioeradication. org/Portals/0/Document/Resources/1st\%2 0Global\%20

CertCom\%20Meeting\%20Report\%20199 6.PDF

7. Thacker N, Vashishtha VM, Thacker D. (2016). Polio Eradication in India: The Lessons Learned. Pediatrics. 138(4):e20160461

8. World Health Organization (WHO). (2010). Poliomyelitis in Tajikistan: first importation since Europe certified poliofree. Geneva. [Accessed 12 Oct 2015].
Available from: http:// www.who.int/wer/2010/wer8518.pdf

9. World Health Organization (WHO). (2014). Polio outbreak in the Middle East update. 21 Mar. [Accessed 9 Dec 2014]. Available from: http://www.who.int/csr/don/2014_3_21po lio/en/

10. World Health Organization (WHO). (2014). Polio outbreak in the Middle East - update. Ongoing transmission in the Syrian Arab Republic with international spread. Disease outbreak news. Geneva: WHO. [Accessed 20 Apr 2016]. Available from:

http://www.who.int/csr/don/2014_3_21po lio/en/

11. European Centre for Disease Prevention and Control (ECDC). (2014). Monitoring current threats: ECDC Communicable Disease Threats Report (CDTR), week 37/2014. Stockholm: ECDC. [Accessed 12 Oct 2015]. Available from: http://www.ecdc. europa.eu/en/press/news/_layouts/forms/ News_DispForm.aspx $?$ List $=8 \mathrm{db} 7286 \mathrm{c}$ fe2d-476c-9133-18ff4cb1b568\&ID=1065.

12. Ather F (2012). Polio eradication, the biggest public health intervention. Khyber Med Uni J 4(4): 147-8.

13. Polio, (2004): https://amhistory.si.edu/polio/timeline/ind ex.htm

14. CDC (Centers for Disease Control and Prevention):

https://www.cdc.gov/polio/us/index.html. (2017).

15. Bodian, D., Morgan, I.M., Howe, HA (1949).Differentiation of Types of Poliomyelitis viruses. II. The Grouping of fourteen strains into three basic immunological types, American Journal of Hygiene, 49:234-245.

16. Smallman-Raynor, MR, Cliff AD, Trevelyan B, Nettleton C \& Sneddon S (2006). Poliomyelitis: Emergence to Eradication, Oxford University Press.

17. Melnick JL (1977). Report of the World Health Organization: Recommendations for the Control of Poliomyelitis in 
Israel, West Bank and Gaza Strip. Report \# EM/VIR/7, $\quad$ EPID/54.

18. Nathanson N \& Kew OM (2010). From emergence to eradication: the epidemiology of poliomyelitis

deconstructed. American $J$ of Epidemiol 172(11): 1213-1229.

19. Wells, C. (1964). Bones, Bodies, and Disease; Evidence of Disease and Abnormality in Early Man. Thames and Hudson, London.

20. Sophie O \& Max R (2017). Historical Perspective of our world. https://ourworldindata.org/polio\#historical -perspective

21. De Jesus NH (2007). Epidemics to eradication: the modern history of poliomyelitis. Virol J 4: 70.

22. Bernier RH (1984). Some observations on poliomyelitis lameness surveys. Rev of Infect Dise 6(Suppl 2): S371-S375.

23. WHO (World Health Organization); (2009). Global Polio Eradication Initiative strategic plan 2009-2013 framework document Geneva.

24. Noori N, Drake JM \& Rohani P (2017). Comparative epidemiology of poliovirus transmission. Scientific Rep 7(1): 17362.

25. Martinez-Bakker, M., King, A. A. \& Rohani P (2015). Unraveling the transmission ecology of polio. PLoS Biol 13: 1-21.

26. Keeling MJ \& Rohani P (2008). Modeling Infectious Diseases in Humans and Animals. (Princeton: Princeton University Press)

27. Okeibunor JC, Akanmori BD, Balcha GM, Mihigo R, Vaz RM \& Nshimirimana D (2013). Enhancing access to immunization services and exploiting the benefits of recent innovations in the African region. Vaccine 31(37): 3772-6;

28. Shah Z, Saad M, Khatak M, Rizwan M \& Idress F (2016). Why we could not eradicate polio from Pakistan and how can we.

https://www.ncbi.nlm.nih.gov/pubmed/28

718581. [cited on 30-0619]
29. Pakistan Polio update-january-2019. (2019)http://polioeradication.org/newspost/pakistan-polioupdate.

30. Polio cases. (2019); www.endpolio.com.pk/polioinpakistan/polio-cases-in-provinces, accessed on 23-04-2019.

31. Elhamidi Y, Mahamud A, Safdar M, Al Tamimi W, Jorba J, Mbaeyi C, et al. (2017). Progress toward poliomyelitis eradication - Pakistan, January 2016September 2017. MMWR Weekly 66: 1276-80.

32. Shakeel SI, Brown M, Sethi S \& Mackey TK (2019). Achieving the end game: employing "vaccine diplomacy" to eradicate polio in Pakistan. BMC Pub Health 19(1): 79.

33. Morales M (2016). Progress toward polio eradication worldwide, 2015-2016. MMWR. Morbidity and Mortality Weekly Rep 65(18): 470-3.

34. Vakili R, Emami-Moghadam Z, Soltani SM, Khakshour A, Khademi G \& Saeidi M (2015). Poliomyelitis: Current status in iran and worldwide. Inter $J$ of Pediatrics 3(3.2): 655-663.

35. Fahmy K, Hampton LM, Langar H, Patel M, Mir T, Soloman C, Hasman A, Yusuf N \& Teleb $N$ (2017). Introduction of Inactivated Polio Vaccine, Withdrawal of Type 2 Oral Polio Vaccine, and Routine Immunization Strengthening in the Eastern Mediterranean Region. J Infect Dis 216 (suppl 1): S86-93.

36. Rehman AU, Sahir I, Yaqoob I \& Zulfiqar $S$ (2017). Factor Affecting Polio Eradication Program in Pakistan. Arabian J Bus Manag Rev 7: 298.

37. Patriarca PA, Wright PF \& John TJ (1991). Factors affecting the immunogenicity of oral poliovirus vaccine in developing countries. Rev of Infec Dis 13(5): 926-939.

38. World Health Organization. (2013). Consultation with Islamic scholars on polio eradication. Islamic Republic of Pakistan.

http://www.emro.who.int/images/stories/p akistan/Consultation. 